expectoration would there be allowed to dry ; for the sisters in charge of the wards and the senior nurses well know the dangers which lie in tuberculous sputum, and are on the outlook for any infıingement of the ward rules which require the patients to expectorate only into the spittoons placed by the side of every bed. In the ont-patients' department those who wait to see the physicians on duty are, of necessity, kept under a supervision which is neither constant nor rigid; nevertheless, it is improbable that expectoration would be allowed to dry on the floors or benches of the out-patients' waiting rooms. We were, therefore, in doubt as to whether we should find evidence of the presence of tuberculous infection in the dust of these rooms; but we should not have been surprised had we found it there. In the dust taken from beneath the fixed table in one of the wards we did expect to find eridence of the presence of tuberculous infection. The table is very large ; and its shape is such as to make the thorough cleaning of the floor below it a matter of much difficulty. Yet we found in the dust below it no evidence of the presence of tuberculous infection. This, we think, is probably due to the fact that the spittoons in use in the ward in question were under constant and careful supervision during the time when the value of tuberculin in the treatment and diagnosis of tuberculous disease was being worked out in the bospital. Therefore, although no special precautions were taken to disinfect and keep moist the spittoons in this ward while tuberculin was undergoing investigation there, it was most unlikely that the drying of the sputum in these spittoons could bave gone on to any dangerous extent, for they were emptied and cleaned with perfect regularity whenever they contained a considerable quantity of sputum, and, in addition to that, once in every twenty-four hours at a fixed time. We are surprised to find that we obtained no evidence of the presence of tuberculous infection in the dust collected in the pathological workroom. We can offer no explanation of this fact, but we think it worthy of being recorded and kept in mind with a view to obtaining some light on it by future experiments. Septicæmia killed so many of our guinea-pigs which had been inoculated with tuberculous sputum three months old that it is not possible for us to record any other observation resulting from this part of our work, because most of the animals died within a week of receiving the injection of stale sputum, so tbat tuberculosis had not time plainly to declare itself. The few guinea-pigs which survived the operation were killed by chloroform inhalation and examined, and of these not one gare any evidence of having developed tuberculosis. This number was, however, too small to be of any real value; yet it is not unimportant to note the fact that five guinea-pigs which had received injections of sputuen three months old, and teeming with tuberculous bacilli, were two months thereafter free from tuberculosis. It was only from the dust taken from the main outcast air shaft of the hospital that we obtained evidence of the presence of tuberculous infection in the course of these experiments. We would remark, in this connexion, that the dust from this source had been submitted to two influences, which, taken together, may possibly have had some favouring influence on bacterial survival and growth in the air shaft. In the first place, the constantly changing air in the outcast sbaft is always well warmed in its passage through the wards of the hospital. In the second place, the bacterial life in the outcast shaft is never exposed to bright sunlight, and, indeed, it can hardly be said to be exposed to light at all.

It is very easy to attach too much importance to the results of research of this kind when it deals with only one handred experiments. We, however, think we are justified in stating that the outcome of our work shows that in the wards and out-patient defartment of a hospital, where a very moderate amount of care is taken to prevent the spread of infection from the expectoration of tuberculous persons, there is, within the limits of our observations, surprisingly little evidence of the escape of tuberculous bacilli to become a source of infection. We venture to hope that, so far as it goes, the result of our work may help to encourage the rigorous enforcement of those precautions, of the meaning of which every phthisical patient ought to have special knowledge, and which are intended to prevent, and evidently do in a measure prevent, the spread of infection from tuberculons sputa. The real value of the hospital and sick-rnom precautions which our $\mathrm{kn}$. wledge of the true ratholngy of tuberculosis teaches us to talse in treating cases of that disease, will be shown in the results of the work, not of one or two only, but of many observers. The gauging of this real value is complicated by the fact that of several matters which closely touch the solution of the question we are still very jgnorant. For example, when pathogenic bacteria are cast out of the body of their victim, and are thus obliged to submit for a time to the chances of a nonparasitic existence, we know that their killing power becomes, in such circumstances, a very uncertain quantity. The uncertainty lies in the direction of loss of virulence. A good illustration of this loss of killing power is to be observed when the anthrax bacillus is taken from an animal's body and cultivated, for a fortnight or so, in gelatine of the ordinary composition. Now, although it is true that the tuberculous bacillus probably retains its virulence at least. as well as any other organism does when it is living a nonparasitic life, still it must be remembered that there exists no experimental proof to guide us where human beings are concerned, and, therefore, it is not known that it follows, that because tuberculous bacilli will kill a guinea-pig, or a rabbit, after the micro-organism has been lying in sputa which have been drying on a floor for, say, six weeks-we say it does not follow that, because the bacilli can do this, they could therefore, in like circumstances, kill a man. It. is known that the anthrax, which will surely kill a guineapig, is not by any means certain to kill an ox. In like manner there exists no proof that the tubercle bacillus which is taken from drying sputum, and which is surely fatal to the guinea-pig, will also kill a human being. It. may be highly probable that it will do so in favourable circumstances, but that is the utmost that can be safely said, within the limits of our present knowledge ; bowever, as we have just said, this very important part of the subject bristles with difficulties, and it can be settled only by the labours of several observers. Exact observations, founded on. experiments properly conducted, will decide the real value of the precautions in hospital and in the sick-room to which we have referred ; and we must wait for much more information than we yet have from those sources before we can feel sure that the recent fall in the death-rate from tuberculosis in England is due to the wider and better knowledge of the pathology of that dire disease which we owe to Koch's great. discovery. We have certainly good reason to hope and to believe that this may be so; and strong cause for urging, upon all whom it may concern, the importance of teaching those who suffer from tuberculosis the duties which they owe to their healthy fellow men.

\section{SUBCONJUNCTIVAL H MORRHAGE LIMITED TO THE OUTER PART OF THE EYE,}

A SIGN OF FRACTURE THROUGH THE CORRESPONDING ORBITAL PLATES.

BY RUTHERFORD MORISON, M.B , F.R.C.S., SENIOR ASSISTANT SURGEON, ROYAL INFIRMARY, NEWCASTLE-ON-TYNE.

THE accompanying illustrations are made from two patients recently under the care of Dr. Hume in the Royal Infirmary, Newcastle-on-Tyne. I am indebted to him for permission to make use of his cases. The drawings illustrate a frequent condition-a roughly fan-shaped bæmorrhage in the outer aspect of the eye-ball. This follows injury to the fore part of the skull and is, I believe, associated-at all events in the great majority of instances-with a fracture through the orbital plate corresponding to the eye affected. Fig. 1 represents the right eye, which alone was affected, in the third wefk after the accident. Fig. 2 represents both eyes of a patient on the seventh day after the accident. The diagnosis made in both, on admission, was fracture of the anterior fossa; but as recovery followed in each case this opinion was not verified by post mortem examination. Three cases in which I had the opportunity of making a post-mortem examination after noting during life the presence of this lesion have served to convince me that this sign is of considerable importance. Hence the present communication. The following are notes of my cares.

CAsE 1.-A boy aged nine years was knocked down by a cart and stunned. On the following day he was running about, appeared to be well, and made no complaint. Ten days 
later he died of pneumonia, apparently the result of cold was seen to extend from the lett of the nilule line above and unconnected with the injury. At the time of his death into the right orbital plate below.

his right eye was in the condition seen in Fig. 1 . At the necropsy a fissured fracture was seen to extend from a little

Fig. 1.

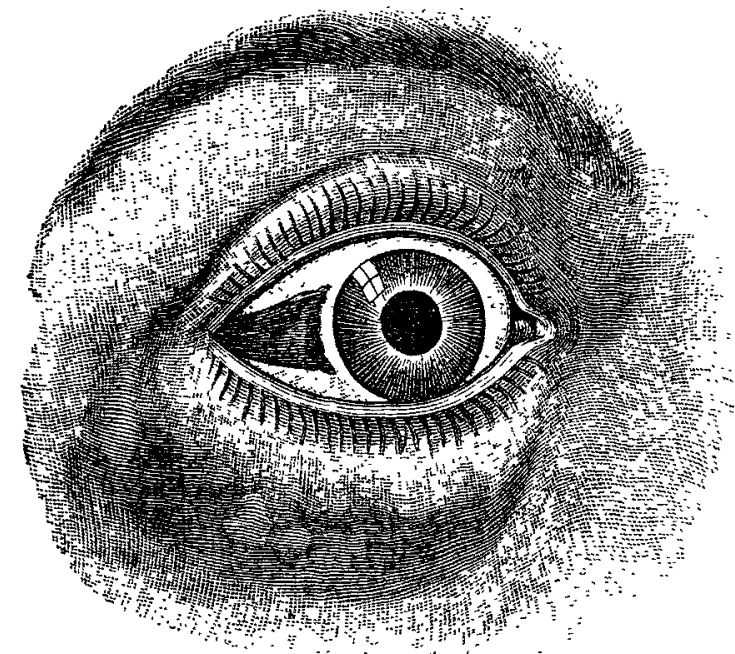

CASE 3.-A man aged forty-five years was admitted to the Royal Infirmary, $\mathrm{N} \in$ wcastle, with a head injury, being unconscious and bleeding from his nose. In two days he recovered consciousness and for two weeks appeared to be going on well. Two days before his death he complained of violent beadache and began to vomit. There was no rise of temperature till four hours before his death. Post mortem a fan-shaped bæmorrhage was noticed on the outer side of both eyes, as in Fig. 2 though in a more advanced stage, as in Fig. 1. An unhealed wound was present over the upper part of the right side of the frontal bone. Under this a fracture was found extending downwards and running through: the right orbital plate, across the ethmoid, into the left orbital plate for about half an inch. A V-shaped fracture extended from the centre of the fissure throngh the right orbital plate into the internal table forming the: posterior wall of the frontal sinuses. The inner table was loose, and the frontal sinuses were full of pus, thus accounting for the purulent meningitis which had eaused death.

Remarks - The shape of the hæmorrhage is not due to the pressure of the lids, for in the patient from whom Fig. 2 is taken, both eyes were closed for some days by extravasation into the lids. Neither is it a bæmorrhage limited by the sheath of the external rectus. Though it is easy to say what it is not, a satisfactory explanation as to why it should be limited to this particular region is more difficult. The presence of a quantity of loose cellular tissue in the outer part of the orbit, and the fact that there is more room here than

above and behind the right external angular process across the right orbital plate of the frontal bone.

CASE 2 -A youth aged eighteen years fell from a scaffuld ing into the hold of a ship (over $30 \mathrm{ft}$.) and, in addition to

FIG. 2.

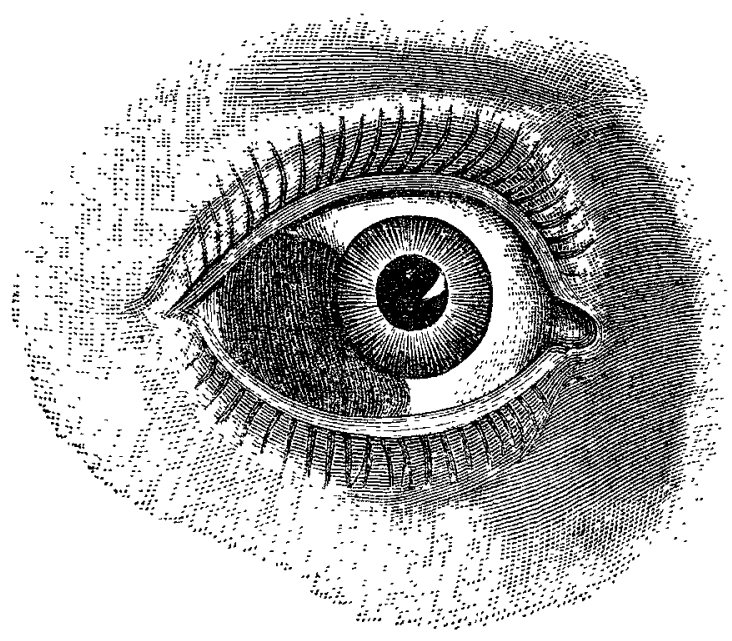

an injury to the head, sustained internal damage, from which he died on the seventh day. A fan-shaped bæmorrhage was present on the outer part of his right eye at the time of his death. At the necropsy a fracture in the right frontal bone

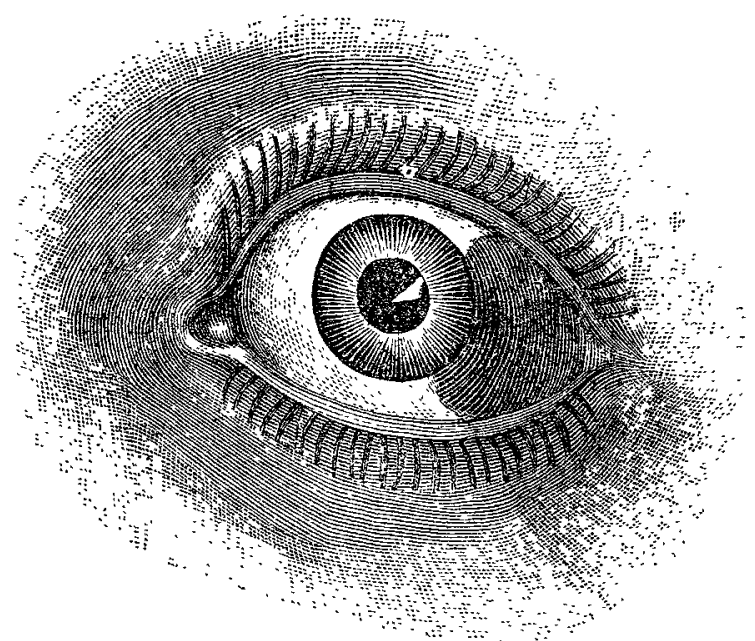

elsewhere, may account for a small hæmorrbage showing itself in this special position, the shape in the later stages, as seen in Fig. 1, being largely determined by the pressure of the lids.

\section{DEATH FROM HÆMORRHAGE INTO THE PERICARDIUM.}

BY JOHN GORDON, M.D. ABERD.,

ASgISTANT TO THE PROFESSOR OF MATERIA MEDICA, ABERDEEN UNIVERSITY, AND PHYSICIAN TO THE ABERDEEN GENERAL DISPENSARY.

THe following case presents some aspects of interest which contrast with the cases recorded in ThE LANCFT of Dec. 2nd, 1893, by Dr. Fraser ; and for these reasons, as well as for the intrinsic interest of the case, it seems to be worthy of record. Buch cases are by no means common, and they present a variety of symptoms that may easily mislead one in the diagnosis.

A man thirty-three years of age, hard-working, steady, and careful in all his life habits, had no history of any special illness. There was no specific disease nor rheumatic tendency. He bad been attended two years ago for a small corneal ulcer. For about two months before the fatal attack he had complained of being more tired than usual at the end of his day's duty; but this be attributed to some extra evening work. A week before his last ilness be had a fainting fit which lasted for a few seconds only; extra work was again blamed. There was no pain complained of then nor at any subsequent time. He did not seek medical advice. At 7.10 P. M. on Saturday, Nov. $25 \mathrm{ch}$, my friend Dr. W. R. Pirie was called to see him and by the kindness of Dr. Pirie the following notes are supplied. The patient had fallen down on the pavement in front of $\mathrm{Dr}$ MacGregor's house; he was carried into the hall and laid down. He was unconscious and breathing deeply; his face was very pale and the lips were slightly blue; the pulse at the wrist was very feeble, being almost imperceptible; the body was covered with cold, clammy perspiration. On examination of the heart by auscultation the sounds were distinct and apparently normal in cbaracter. In a few minutes after the administration of a stimulant (whisky) he partially recovered consciousness and was able to give his name and address, and gradually consciousness entirely returned. Dr. Macgregor now saw him, and to him be stated that be had hurried into town to keep an engagement. At that moment he said he was feeling sick and romited some food. He became very restless, tossing his limbs about, but after a short time he was quiet. After watching him for half an hour be was able, and expressed himself anxious, to be sent home in a cab. He was fit, with slight assistance, to walk into his house, to undress and go to bed, where he almost immediately involuntarily passed a motion, and a little later this was repeated; he also passed urine. $H_{2}$ now began to complain 